\title{
The Correlations between Health Behaviors and the Use of Health-Preserving Mobile Applications in Young Adults
}

\author{
Zsolt Námesztovszki ${ }^{1}$, Lenke Major ${ }^{1}$, Cintia Kovács ${ }^{1}$, Dijana \\ Karuović ${ }^{2}$ and György Molnár ${ }^{3}$
}

${ }^{1}$ University of Novi Sad, Hungarian Language Teacher Training Faculty, Subotica 424 Strosmajerova 11, 24000 Subotica, Serbia

E-mail: \{zsolt.namesztovszki, major.lenke, cintia.kovacs \}@magister.uns.ac.rs

${ }^{2}$ University of Novi Sad, Technical faculty "Mihajlo Pupin” in Zrenjanin

Zrenjanin, 23000 Novi Sad, Serbia

E-mail: \{dijana.karuovic\} @ at tfzr.uns.ac.rs

${ }^{3}$ Budapest University of Technology and Economics

Magyar tudósok körútja 2, Q building, Budapest, Hungary

E-mail: \{molnar.gy\}@eik.bme.hu

\begin{abstract}
Individuals' lifestyles manifest themselves in daily activities that can have effects that are a health-preserving, preventive or risk-enhancing, in terms of health. Some of them are simple everyday activities, as eating, exercising or smoking, which are closely related to health without being specifically viewed as health-related behaviours. In the case of university-age young people, a similar activity that affects health is the use of smart devices. Like any other factor, this can also have both positive and negative impacts on health.

In this study, we looked at the health status of university-age young people, as well as their habits in using smart applications. The results have shown that the health of university students studying in Serbia and Hungary is satisfactory in several respects. In addition, several correlations can be seen between their general well-being, their exercise and eating habits, as well as their use of smart devices, applications, more specifically, applications aimed at health-care.
\end{abstract}




\section{Introduction - Health-Care}

\subsection{The Concept of Health-Care and the Influence of Lifestyle Factors on Health-Care}

In a health psychological approach, health-care refers to personal attributes of an individual for maintaining, restoring health, and having significant social and community, social and cultural determinants [7].

There are two types of health behavior [5]. The first is positive health behavior, which includes activities contributing to maintaining or restoring health. The second type is health-risk behavior. These are activities that, when practiced, increase the chance of developing a disease or injury [7]. Lifestyle factors such as nutrition, physical exercise habits or smoking, drugs and alcohol have a significant impact on a person's health.

Nowadays, one of the main goals of researches related to health psychology is to identify and test in practice those factors, theoretical models and programs that may be the most effective ways of changing health behavior [1].

Regular physical activity is one of the most effective protective factors against the most common chronic diseases, cardiovascular disease. In addition, the nutrition of an individual has a significant impact on health, too.

In the last decade, parallel to studies on lifestyle factors, research into the impact of psychosocial factors on health status has come into view. These mental healthrelated factors primarily influence mental health, but also physical health. Psychosocial risk factors include social inequalities, unemployment, social deprivation, work, and family stress, and depression. These have a significant impact on the morbidity and mortality rates of the group [3].

\subsection{Relationships between the Online Educational Environment and Health Behaviours}

There are many places for realizing health promotion strategies, the most important of which is the place where education is provided, i.e., the online learning environment provided by educational institutions and ICTs [8].

The key aspect of developing good health behavior is relevant information. The appearance of smartphones has been one of the greatest steps in gathering information, accessing a variety of data and using common IT applications [4]. These tools are now an important aid in shaping young people's health behaviour [12]. 
Promising opportunities for online health-care are offered not only by the Internet, and social networks, but also more and more frequently by various mobile apps [6].

There are apps, which measure blood pressure or blood sugar, calculate how many steps one ought to take each day, or how much water one should drink. There are certain apps that monitor how long one's deep sleep phase is at night, others will warn the user to exercise regularly or limit their calorie intake.

\section{The Correlations between Health-Care and the Use of Mobile Health Applications}

\subsection{Aim of Research}

The spread of smartphones provides new forms of health communication and diverse opportunities for educating healthy lifestyles. Health-care applications can also be an important aid in shaping young people's health behaviours. The aim of our research is to investigate if health behaviours and the variables determining the general health status of students can be related to the frequency of using health-care mobile applications.

\subsection{Research Hypotheses}

H1: The health behavior of the majority of students ( $75 \%$ of the sample) is satisfactory.

$\mathrm{H} 2$ : Students whose health status is satisfactory use health-care mobile applications less.

H3: The majority of students, who exercise frequently, use some kind of proven mobile application.

H4: Students with satisfactory eating habits use smartphone applications significantly more than those who, according to their own admission, are not eating properly or are not interested in a balanced diet.

\subsection{Method}

The study involved four higher educational institutions from Hungary and Serbia. The online survey was completed in January 2019. The questionnaire was distributed to students in two languages, either Hungarian or Serbian, depending 
on the language of teaching at the specified institution. The questionnaire consisted of 5 sections. The first section examined the general (background) data of the students. The second to fourth sections asked students about their general health, sports, and nutrition habits. The fifth part of the questionnaire included questions related to the use of mobile devices and mobile health applications. The questionnaire survey was prepared online using the google form, which is available here:

https://docs.google.com/forms/d/16Vsaf7PUctnyC6whBJUw8dURm8TldmpK9c MRKQNk380/edit

\subsection{Sample}

Students from higher education institutions in Serbia and Hungary were included in the research. A total of 329 students participated in the survey.

Background data of the sample

(1) Gender: $40 \%$ of subjects were male $(\mathrm{N}=130)$ and $60 \%$ female $(\mathrm{N}=198)$.

(2) Institutions involved in the investigation:

The students of three Serbian (SRB) and one Hungarian (HU) institutions took part in the study. The distribution of students by institution is illustrated in Table 1.

Table 1

Institutions

\begin{tabular}{llcc}
\hline & & $\mathrm{N}$ & $\%$ \\
\hline SRB & TFZR (Technical Faculty "Mihajlo Pupin") & 166 & 50 \\
& $\begin{array}{l}\text { MTTK (Hungarian Language Teacher } \\
\text { Training) }\end{array}$ & 87 & 27 \\
& $\begin{array}{l}\text { VTŠ (Subotica Tech - College of Applied } \\
\text { Sciences) } \\
\text { BME (Budapest University Of Technology }\end{array}$ & 16 & 5 \\
And Economics)
\end{tabular}

Language of teaching

Among the students in the sample, there were students from Hungary whose language of instruction is Hungarian. Participants from Serbia included students whose language of education is either Hungarian or Serbian. The authors examined the differences in the results of students studying in each language of instruction.

Two categories were created based on the variables: 
Students studying in their native language in their country: $69 \%(\mathrm{~N}=228)$

Students studying in a minority language in their country: $31 \%(\mathrm{~N}=101)$.

Studies:

Teaching: $42 \%(\mathrm{~N}=139)$

Computer Science: $29 \%$ ( $\mathrm{N}=95)$

Engineering: $26 \%(\mathrm{~N}=85)$

Economics: $3 \%(\mathrm{~N}=10)$

\subsection{Results of the Research}

\subsubsection{Health Behaviors, General Well-Being}

Students were asked about their general health using a five-level Likert scale. The average score on the scale: 4.09 points (standard deviation 0.72 ) out of a possible 5 points. On the scale, the score of 2,5 represents the neutral limit. Anything below represents students' negative attitude towards health, while anything above represents a positive attitude. The value obtained shows that the majority of students have a positive opinion of their health status. (see Figure 1)

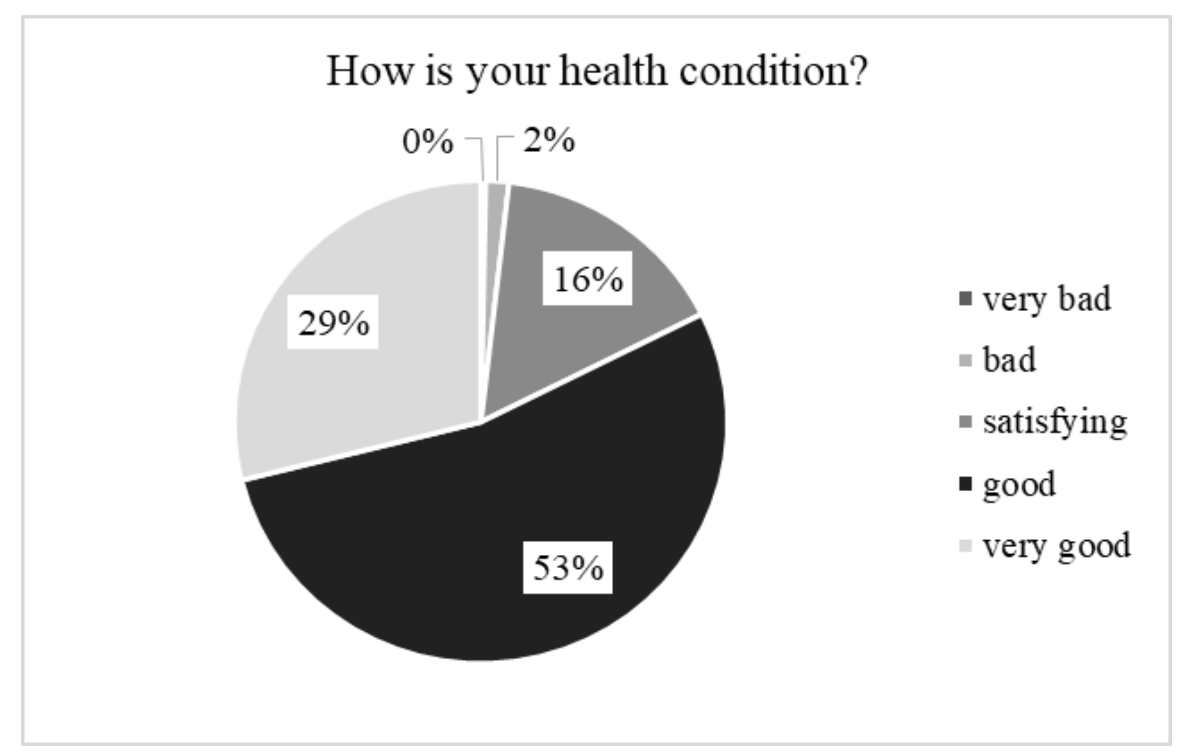

Figure 1

The general health of students 
Of the surveyed students, $21 \%$ are suffering from some kind of chronic illness, while $79 \%$ of them claim they are completely healthy.

We asked the students about their available options, and what they can do in order to preserve their health. They could answer the question on a four-level Likert scale, where 1 means they can't do anything, and 4 means they can do very much. There was only one student who said they couldn't do anything to preserve their health. 15 students (5\%) said they could only do a little. 178 students (54\%) claimed they could do a lot, while 135 students (41\%) claimed they could do very much in order to preserve their health.

A total of $18 \%$ of the surveyed students stated they were regular smokers, $10 \%$ occasionally and $72 \%$ were non-smokers.

The recorded results in regards to health behaviours support hypothesis H1. The surveyed students are in a good state of general well-being, the majority does not suffer from any chronic illnesses, and only a few of the surveyed students smoke, and according to their own admission, they can do much to preserve their health.

\subsubsection{Exercise Habits}

Students were asked about their exercise habits using a five-level Likert scale. Based on the results, $35 \%$ of students exercise several times a week, $11 \%$ admitted to not engaging in any physical activity at all, while the others exercised in different frequencies. The majority of students $(79 \%)$ do not have a personalized training plan, and only $11 \%$ are professional athletes.

The majority of the surveyed, $46 \%$ exercise in order to stay in shape. $34 \%$ of the students exercise because they enjoy the physical activity. While a lot less, $16 \%$ in total, only exercise because they wish to lose weight. Only $4 \%$ of them exercise because it is either their profession or they do it competitively.

While the majority of the surveyed students use walking as their exercise. Cycling, jogging, and bodybuilding are also common forms of exercise among them. However, more students cited swimming, football, and aerobics as their favorite form of exercise. (see Figure 2) 


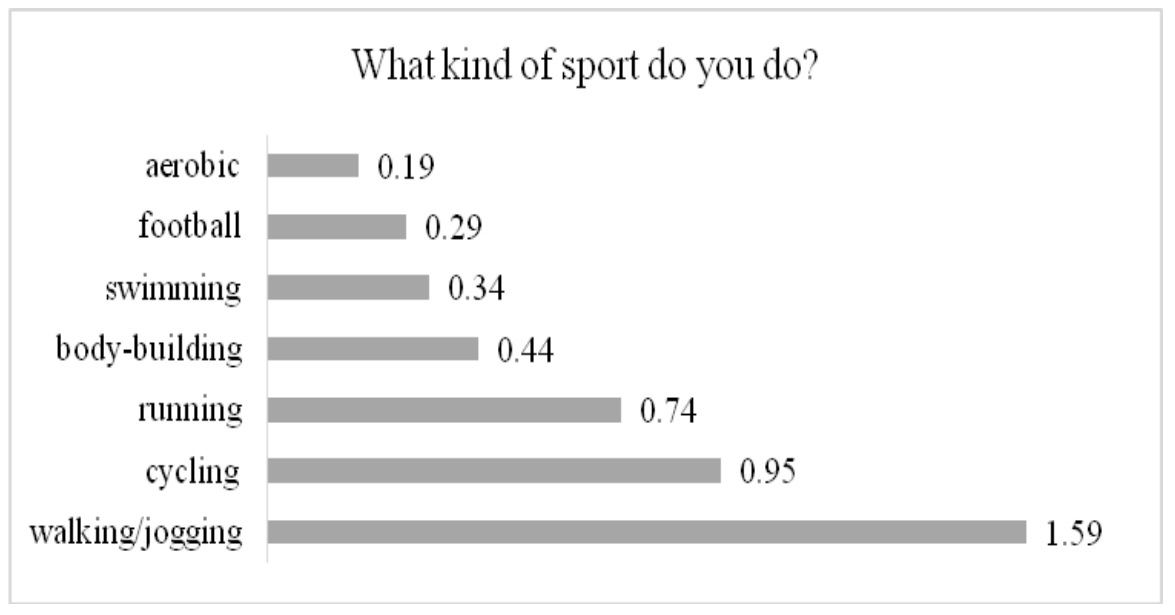

Figure 2

The general health of students

\subsubsection{Eating Habits}

Body mass index (BMI) is widely used to determine healthy body weight, overweight or leanness. BMI is a statistical measure calculated by dividing body weight in kilograms by the square of height in meters [7].

For $60 \%$ of the students in the study, the BMI index averaged 23.9, which means normal weight. $5 \%$ of the students were below normal weight, and $27 \%$ were overweight. A total of 20 students were Class I, 5 students were Class II, and one student was Class III of obesity (Table 2). The table is based on the levels of the BMI scale used by the World Health Organization [10] [11], where the body mass index values are ranked on a 6-level scale [9] (see Table 2).

Table 2

Students' body weight based on BMI scale values

\begin{tabular}{lcc}
\hline BMI $\left(\mathbf{k g} / \mathbf{m}^{\mathbf{2}}\right)$ & $\mathbf{N}$ & $\mathbf{\%}$ \\
\hline$<18,5:$ Underweight & 17 & 5 \\
18.5-24.9: Normal & 197 & 60 \\
25.0-29.9: Overweight & 89 & 27 \\
30.0-34.9: Obese Class I & 20 & 6 \\
35.0-39.9: Obese Class II & 5 & 2 \\
40 > Obese Class III (Very severely obese) & 1 & 1 \\
\hline
\end{tabular}

The results of students studying in Hungary and Serbia show differences in BMI, nutrition and the number of used mobile apps. The average BMI index for 
students studying in Hungary is 25.3, which belongs to the overweight category. In contrast, students studying in Serbia have a significantly lower BMI index $(\mathrm{t}=$ $2.83 \mathrm{p}=0.005$ ). This group presented an average of $23.6 \mathrm{BMI}$, which belongs to the normal weight category.

The majority of the students, $37 \%$, felt that their nutrition was unbalanced. $28 \%$ are not concerned about the issue, or do not care. Only 35\% of the respondents stated that their nutrition was balanced. Regarding nutrition, Hungarian students considered their own nutrition habits much unhealthier than Serbian students $(\mathrm{t}=$ $3.23 \mathrm{p}=0.001)$.

Regarding the form of food, many of the respondents prefer meat, fresh fruits and vegetables, and dairy products to sweets, snacks, fruit juices or energy drinks.

The received results proved hypothesis $\mathrm{H1}$, the health-care behavior of the interviewed students is satisfactory in regard to general health. The general wellbeing of the surveyed students is satisfactory, most of them don't suffer from any chronic illnesses, only a few of the surveyed are smokers, and according to their own admission, they can do very much in order to preserve their health. The majority of the students exercise on a regular basis, although only a few of them do it in a competitive manner. The results indicate that their health behavior is satisfactory in terms of exercise habits as well. Most of the students' BMI index falls into the normal category. Despite the fact that the majority of students admit that their diet is unbalanced, the respondents prefer healthy foods over unhealthy ones.

\subsubsection{Results Related to the Use of Smartphones and Health-Care Applications}

Most of the surveyed students use some kind of smart device, most of them (68\%) use a smartphone with an Android operational system (Figure 3).

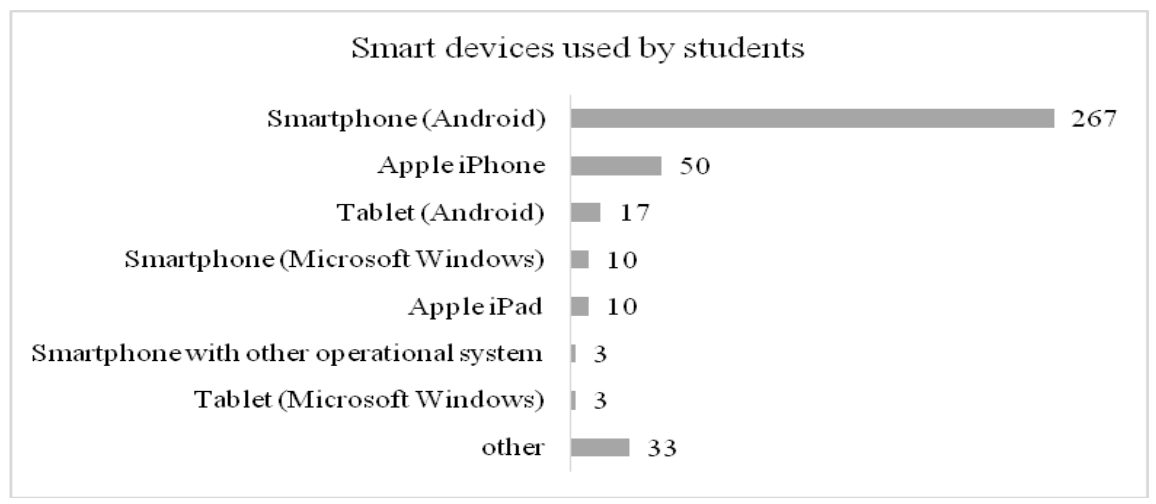

Figure 3

The most commonly used smart devices 
Most of the students (39\%) use between 6 and 10 apps on their smart devices. $23 \%$ use between $11-20$ and $13 \%$ between $21-40.4 \%$ of the respondents regularly use more than 40 applications, and $21 \%$ use 5 or fewer applications (see Table 3 ).

Table 3

Number of used smart applications

\begin{tabular}{ccc}
\hline number of installed applications & N & $\%$ \\
\hline 5 or less & 68 & 21 \\
$6-10$ & 127 & 39 \\
$11-20$ & 77 & 23 \\
$21-40$ & 44 & 13 \\
more than 40 & 13 & 4 \\
\hline
\end{tabular}

The results of the two-sample t-test show no gender difference in health awareness. There are no differences between the two genders in the use of healthcare applications. The only difference detected was in the number of used mobile applications. Men use significantly more applications than women $(\mathrm{t}=2.93 \mathrm{p}=$ $0.004)$.

$67 \%$ of the surveyed students use some kind of health-care application. The most frequently used applications are the Cycle Calendar and other fitness and health applications. Also, often used applications are Huawei/Samsung Health, Pedometer, Fitness, Yazio, Health, Calorie Base, Endomondo (see Figure 4). Concerning the number of mobile applications, students studying in Hungary use significantly more applications than students studying in Serbia $(t=3.97 \mathrm{p}=$ 0.001). Students in the economics study programs use significantly more applications than students in the other three programs (teacher-training, IT, engineering $)(\mathrm{F}=6.14 \mathrm{p}=0.001)$.

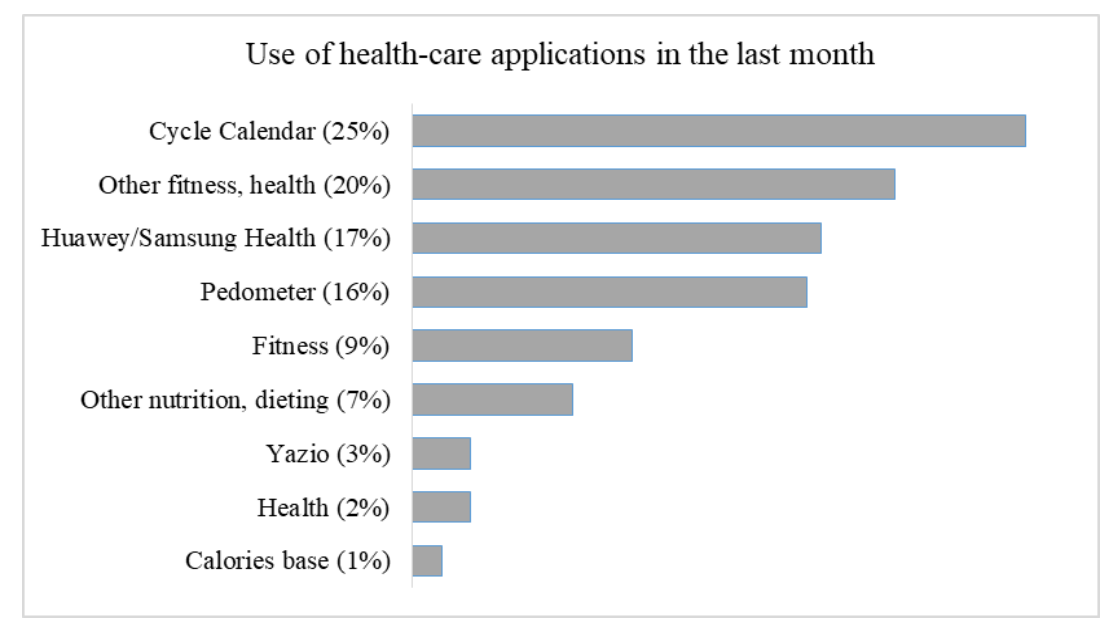

Figure 4

Health-care applications used by students 
We examined whether students in good health (those who fall into the groups of satisfactory, good or very good) use any more health-preserving applications than those who have an unsatisfactory health status. We found that those in good health use less health-preserving applications $(t=-2,75 \mathrm{p}=0,006)$. Based on the results we can conclude that the use of a few specifically selected, proven applications that have a real positive effect on health are much more expedient than the effects of randomly downloaded, infrequently used applications.

From the students who work out regularly (once or multiple times a week, or daily) $61 \%$ use a smart application, of which $39 \%$ use apps related to fitness, exercise or physical activity. Here, as well, the number of those who do use such applications, but only less than 5, were significantly higher $(\mathrm{t}=-3,02 \mathrm{p}=0,01)$.

\subsubsection{The Correlations between a Healthy Lifestyle and the Use of Health- Preserving Applications}

We examined whether students in good health (those who fall into the groups of satisfactory, good or very good) use any more health-preserving applications than those who have an unsatisfactory health status. Pearson's correlation study has shown that there is an inverse correlation between general health and the number of health care applications used $(\mathrm{r}=-0,14 \mathrm{p}=0,009)$. The correlations are supported by the two-sample t-test as well. Based on the results, we found that students in good health use less health-preserving applications $(\mathrm{t}=-2,75 \mathrm{p}=0,006)$. These values support hypothesis $\mathrm{H} 2$, meaning that the use of a few specifically selected, proven applications that have a real positive effect on health is much more expedient than the effects of randomly downloaded, infrequently used applications.

From the students who work out regularly (once or multiple times a week, or daily) $61 \%$ use a smart application, of which $39 \%$ use apps related to fitness, exercise or physical activity. The frequency of exercise shows a significant correlation with the use of health-preserving applications $(\mathrm{r}=0,11 \mathrm{p}=0,04)$. According to the two-sample t-test, the number of those who do use such applications, but only less than 5 , were significantly higher $(t=-3,02 \mathrm{p}=0,01)$. These results confirm hypothesis $\mathrm{H} 3$.

The studies have shown that students who have a balanced diet use a lot more health-preserving applications $(\mathrm{t}=2,14 \mathrm{p}=0,04)$, than those who, according to their own admission, are not eating properly or are not interested in a balanced diet.

The above results prove our statement in hypothesis H2. Students in satisfactory health, who exercise regularly and have satisfactory eating habits use significantly more health-preserving smartphone applications than students with health problems. 


\section{Summary of Research Results}

The examination of the students in the sample has revealed that the health behavior of students is satisfactory, even according to their own admission. There are only a few who suffer from a chronic illness or smoke on a regular basis. They are aware of their available options, which can help them in preserving their health, and the majority does take advantage of these options. The results have shown that the majority of students do partake in physical exercise, although with varying regularities. Most of them take walks, but a wide range of other forms of exercise were also noted during the survey. In terms of their body mass index, the participating students fall into the normal body weight category and have satisfactory eating habits.

The majority of students participating in the survey do use a smart device and mobile applications. We were able to find multiple correlations between the use of such applications and the health behaviours of students. Those who consider themselves less healthy download more of these applications, while students with satisfactory health statuses still use health-preserving applications, but only a limited number of them, and in a more conscious manner. Young people who exercise regularly also have their proven applications, which they use often, while students with balanced diets also demonstrate the use of such health-preserving applications. There have been similar studies in the past in the same topic that have confirmed our own research [13].

\section{Conclusion}

The most important goal of comprehensive health promotion is that everyone from the youngest to the oldest age should take part in systematic health promotion activities that effectively contribute to full physical and mental well-being and health. Any widely-used development activity must take advantage of the achievements and tools of ICT. The modern ICT based tools applicable in the field of VR and AR [14]-[16], gamification or cooperative techniques [17]-[19] and other field of Cognitive Infocommunications [20]-[25].

The use of smart devices in health promotion does not hamper health-conscious behavior but supports and develops the user's goal of pursuing a healthy lifestyle.

The use of health-related applications facilitates the acquisition of information, can trigger changes in health attitudes, reveal new opportunities, and aid the users on their path towards a healthy lifestyle.

The results of our research support the assumption that the use of mobile applications can help university students to develop and maintain a healthy lifestyle, regular physical activity, and healthy nutrition habits. This field requires continued research: as this work has shown, the views of university students must be taken into account when developing mobile applications and even in designing 
comprehensive health promotion programs. We are planning to expand the scope of the survey in the future.

\section{References}

[1] Fehér András (2016) Exploring on-line consumer behaviour in connection with the food industry, (PhD dissertation) Debrecen University, Károly Ihrig Doctoral School of Management and Business, Debrecen

[2] Glanz, K., Rimer, B. K., Viswanath, K. (eds.) (2008) Health behavior and health education. Theory, research and practice. Jossey-Bass, A Wiley Imprint, San Francisco

[3] Kopp Mária, Kovács Mónika Erika (eds.) (2006) The quality of life of the Hungarian population at the Millennium. Semmelweis Publishing and Multimedia Studio, Budapest

[4] Liu, C., Zhu, Q., Holdoyd, K. A., Seng, E. K. (2011) Status and trends of mobile-health applications for iOS devices: A developer's perspective. Journal of Systems and Software, 84 (11), 2022-2033

[5] Matarazzo, J. D., Millner, N. E., Weis, S. M. és Herd, J. A. (1984) Behavioral Health: A Handbook of Health Enhancement and Disease Prevention. John Wiley, New York

[6] Molnár Regina, Sági Zoltán, Fejes Zsuzsanna, Töröcsik Kálmán, Köves Béla, Paulik Edit (2017) Means of health-related information acquisition from the patient population of special ambulatory medical services. Metszetek, 6 (2), 2063-6415

[7] Ng, Nelson, Farkas Anna, Mészáros János, Mohácsi János (1995) The body mass index as a simple attribute of body composition (?). Kalokagathia, 33 (1), 30-39

[8] Veresné Balajti Ilona (2010) Health status and health-related behaviour of university students, (PhD dissertation) Debrecen University, Doctoral School of Health Sciences, Debrecen

[9] World Health Organizations (2000) WHO Technical Counsultation. Obesity: preventing and managing the global epidemic. Report of a WHO consultation 2000, Report No.: 0512-3054 (Print) 0512-3054, 2000

[10] World Health Organizations (2004) Global strategy on diet, physical activity and health. 57 $7^{\text {th }}$ World Health Assembly, WHA 57.17 Agenda Item 12.6, Geneva

[11] World Health Organizations (online) Body mass index - BMI. Source: http://bit.ly/31OK1K8 [2019.06.21.]

[12] Zoltán Balogh, Milan Munk, Milan Turcáni (2011) Analysis of Students' Behaviour in the Web-based Distance Learning Environment, Recent 
Researches in Circuits, Systems, Communications and Computers, pp. 339344

[13] Jing Zhao, Becky Freeman, Mu Li: Can Mobile Phone Apps Influence People's Health BehaviorChange? An Evidence Review, Journal of medical internet research, Vol. 18, Iss. 11, pp. 1-12, doi: 10.2196/jmir.5692

[14] Ildikó Horváth: Evolution of teaching roles and tasks in VR/AR-based education, Proceedings of the $9^{\text {th }}$ IEEE International Conference on Cognitive Infocommunications (CogInfoCom), Budapest, 2018, pp. 355360

[15] Adam Csapo, Ildiko Horvath, Peter Galambos and Peter Baranyi: VR as a Medium of Communication: from Memory Palaces to Comprehensive Memory Management, Proceedings of the $9^{\text {th }}$ IEEE International Conference on Cognitive Infocommunications (CogInfoCom), Budapest, 2018, pp. 389-394

[16] Laszlo Bognar, Eva Fancsikne, Peter Horvath, Antal Joos, Balint Nagy, Gyorgyi Strauber: Improved learning environment for calculus courses, Journal of Applied Technical and Educational Sciences, Vol. 8, No. 4, 2018, pp. 35-43

[17] Robert Pinter, Sanja Maravic Cisar: Measuring Team Member Performance in Project Based Learning, Journal of Applied Technical and Educational Sciences, Vol. 8, No. 4, 2018, pp. 22-34

[18] Ilona Heldal, Carsten Helgesen: The Digital HealthLab: Supporting Interdisciplinary Projects in Engineering and in Health Education, Journal of Applied Technical and Educational Sciences, Vol. 8, No. 4, 2018, pp. 421

[19] Cs. Rigóczki, A. Damsa, K. Györgyi-Ambró: Gamification on the edge of educational sciences and pedagogical methodologies, Journal of Applied Technical and Educational Sciences, Vol. 7, No. 4, 2017, pp. 79-88

[20] Attila Kovari: CogInfoCom Supported Education: A review of CogInfoCom based conference papers, Proceedings of the $9^{\text {th }}$ IEEE International Conference on Cognitive Infocommunications (CogInfoCom), 2018, pp. 233-236

[21] Peter Baranyi, Adam Csapo, Gyula Sallai, Cognitive Infocommunications (CogInfoCom), Springer International Publishing Switzerland, 2015, p. 219

[22] Dalma Geszten, Anita Komlódi, Károly Hercegfi, Balázs Hámornik, Alyson Young, Máté Köles, Wayne G Lutters: A Content-Analysis Approach for Exploring Usability Problems in a Collaborative Virtual Environment, Acta Polytechnica Hungarica, Vol. 15, No. 5, 2018, pp. 6788 
[23] Gergely Sziladi et al.: The analysis of hand gesture based cursor position control during solve an IT related task, $8^{\text {th }}$ IEEE International Conference on Cognitive Infocommunications, 2017, pp. 413-418

[24] Tibor Guzsvinecz, Veronika Szucs, Cecilia Sik-Lanyi: Suitability of the Kinect Sensor and Leap Motion Controller - A Literature Review SENSORS, Vol. 19, No. 5, 2019. pp. 1072-1097

[25] Gogh, E., Kovari, A.: Metacognition and Lifelong Learning: A survey of secondary school students, $9^{\text {th }}$ IEEE International Conference on Cognitive Infocommunications, 2018, pp. 271-276

[26] I. Horváth: Innovative engineering education in the cooperative VR environment, $7^{\text {th }}$ IEEE Conference on Cognitive Infocommunications, 2016, pp. 359-364 